\title{
ADJUSTING COST OF CAPITAL FOR RISKY ASSETS NOT IN THE RATE BASE
}

\author{
Andre R de Oliveira a, Paulo Coutinho ${ }^{b}$, Alexandre Carvalho ${ }^{c}$ \\ a Utah Valley University, Orem, USA \\ b Universidade de Brasilia, Brasilia, Brazil \\ c IPEA, Brasilia, Brazil \\ Corresponding email: aoliveira@uvu.edu
}

\begin{abstract}
This paper identifies an underappreciated source of risk for capital invested in regulated markets and proposes a new methodology to calculate the associated premium. The risk stems from the impact on the revenues and costs of regulated companies of fully depreciated assets that are still in service, but are no longer included in their rate base. The future of many regulated sectors depends on their ability to attract private investment, which will not materialize if investors are not adequately compensated for bearing that type of risk. We develop three models, one based on financial analysis and two on economic analysis, to calculate the proper rate of return on a fully depreciated plant still in service. $\mathrm{T}$ he financial model builds upon the intuition that this problem is similar to that of determining the appropriate return on risky ventures that do not require capital expenditure. The economic model is based on the idea of opportunity cost. Shareholders of a regulated company have two options: They can either keep the fully depreciated plant in service or replace it with new plant. The regulatory revenue the company is allowed to earn should make shareholders indifferent between the options of replacing or not replacing the fully depreciated assets. The three models generate the same return on capital for investors.
\end{abstract}

Keywords: Fully Depreciated Assets, Opportunity Cost, Rate Base, Return on Capital, Risk.

\section{Introduction}

One of the most contentious stages of the price control review of a regulated utility is the calculation of the appropriate return on capital. It involves the determination of what should be included in the company's rate base, and the rate of return to be applied to that rate base. The product of the rate base and the rate of return equals the company's allowed return on capital, also called its cost of capital (OFGEM, 2010). The future of many regulated sectors hinges upon their ability to attract sufficient private investment, which is of course tied to the cost of capital. This puts a lot of pressure on regulators to "get it right" when setting the allowed return. In general, regulators have to balance two conflicting goals: (i) the return must be acceptable to investors; and (ii) the return must be such that the regulated price paid by users is reasonable.

In developing countries, the calculation of the regulatory cost of capital is even more challenging. Since capital markets there usually are not fully developed, regulators use data from utilities that operate in developed countries to first compute an "international rate of return" (using established methods such as the Weighted Average Cost of Capital (WACC) and the Capital Asset Pricing Model - CAPM (Sharpe, 1964; Lintner, 1965)), and then add the risks of doing business in a developing country. One of the underlying assumptions of this methodology is that the composition of the rate base is similar across utilities that operate in different 
environments, which is not necessarily the case. For instance, regulated utilities in many developing countries have a considerable number of assets still in service that are not included in their rate base, a situation that is not common in developed markets.

Assets still in service but out of the rate base can be classified into two types: Plant that has already been fully depreciated, and plant that is not owned by the regulated company. In the Brazilian electricity sector, for instance, many assets have an economic life that far exceeds their regulatory (or accounting) life. Plant in service that is not owned by the regulated company is a less common occurrence, but in Brazil they make up a significant part of the assets of some electricity distribution companies. There is a special category of assets, called Special Obligations, that are acquired through funds that originate either from the government or from fees paid by users, and as such do not belong to the utility. These assets are used by electric utilities in Brazil to provide service to low income families. In this paper, however, we study only fully depreciated plant that is still in service.

As will be explained later, the presence of fully depreciated plant still in service but out of the rate base creates risk for investors, since it affects the revenues and costs, and hence the profits, of regulated companies. However, the regulatory rate of return earned by investors does not compensate them for this risk, which creates at least two problems. First, investors who have equity in regulated companies in this situation have an incentive to replace fully depreciated but still operational plant with new assets, an unnecessary cost to be borne by users. Second, potential investors will not put their money into regulated sectors where they are not adequately compensated, which will have a negative impact on investments by utility companies.

In this paper, we explain in detail why fully depreciated plant in service represents additional risk for investors and develop a methodology to calculate the adequate compensation for that risk. Our methodology is comprised of three models, one based on a financial approach, and two based on an economic approach. They all lead to the same compensation for the risk generated by fully depreciated plant.

It was surprising to find out that there is no literature, in Finance or the Economics of regulation, that studies exactly the same problem we tackle in this paper. The closest literature we were able to find is that on regulatory risk and stranded assets. Regulatory risk is the risk investors face because regulators might issue norms and regulations that have financial implications for the regulated companies (Kolbe, et al., 1993). The stranded asset literature studies how utilities should be compensated for investments that turned out to be neither used nor useful in the provision of the regulated service (Hausman \& Myers, 2002; Crew \& Kleindorfer, 1999; Joskow, 1996). The problem of stranded assets was particularly important in countries that decided to open regulated sectors to competition.

The paper proceeds as follows. In section 2, we give a brief and general description of the issue of returns on risky ventures that do not require capital expenditures. In section 3, we focus on regulated sectors and explain where the risks associated with regulatory assets that are not part of the rate base originate. In section 4, we describe the methodology to calculate the rate of return on fully depreciated assets still in service and interpret the results. In section 5, we provide our concluding remarks. 


\section{Return on risky ventures with no capital investment}

The theory of Finance posits that the return on an investment can be split into two parts: A liquidity premium and a risk premium. The liquidity premium reflects the average intertemporal preference of investors, who normally place a higher value on the present than on the future. The liquidity premium is the same as the risk-free interest rate, typically measured as the interest rate paid by US Treasury bonds.

Investors are also usually risk averse and thus demand a risk premium, in addition to a liquidity premium, to invest in risky assets. The sum of the liquidity and risk premiums is called the (expected) rate of return, and can be written $E\left[r_{i}\right]=r_{f}+r_{i}^{r}$, where $E\left[r_{i}\right]$ is the expected rate of return of asset $i, r_{f}$ is the risk-free interest rate, and $r_{i}^{r}$ is the risk premium.

When a venture does not require any capital investment but the investor bears risk, the rate of return is given simply by $E\left[r_{i}\right]=r_{i}^{r}$. An example would be a business whose only inputs are temporary workers and a telephone (to get in touch with employees and clients). There is no capital investment (other than the negligible value of the telephone), but the owner bears risk. There is risk because the business may fail to deliver its product or service, which entails fees and/or other penalties, when, say, one or more of its employees do not show up for work. Or maybe the owner is not able to pay the employees because his clients did not pay on time. An entrepreneur will only enter a venture like this if his remuneration is significantly greater than the fixed income he could earn by simply supplying temporary workers for the company.

Another example is an insurance company, which can also be seen as a venture with no initial capital investment (if we ignore its facilities). When it sells an insurance policy, the company does not make any investments. On the contrary, it receives a premium from the insured. The company does, however, bear the risk of having to pay for covered losses, and will calibrate the value of the premium to account for that.

\section{Risks generated by regulatory assets not in the rate base}

In this paper, we are mostly concerned with fully depreciated plant in service that is not in the rate base of the utility company. Our motivation to study this topic comes from the Brazilian electricity sector, where the majority of distribution companies own assets that do not earn any return even though they are still in service. In what follows, we show that they add risk to the business, even though there are no capital costs for the utility company, and discuss how to determine the adequate compensation for the added risk.

In Brazil, as in many countries that use either rate of return or price cap regulation, the required revenue of an electricity distribution company is given by the formula

$$
R=\sum_{i=1}^{n} p_{i} q_{i}=A \cdot r+C+D+T,(\text { Kahn, 1998) }
$$

where $R$ is revenue, $p_{i}$ is the price of good or service $i, q_{i}$ is the quantity of the $i^{\text {th }}$ product or service, $n$ is the number of products or services the company produces, $A$ is the rate base, $r$ is the rate of return, i.e., the (estimated) cost the company incurs to finance its rate base (including debt and equity), $C$ is O\&M, $D$ is depreciation and $T$ are taxes that are not a part of O\&M and are not levied directly on the consumers. 
The rate base includes only assets that are not full depreciated, thus the return on capital investors receive does not vary with the amount of FDP still in service (FDPS from now on). These assets carry risks, however, and investors should be compensated for bearing them. The risk for investors comes from the impact of FDPS on operational revenues and costs. The existence of FDPS inflates the company's costs, which in turn, according to formula (1), increases its required revenue. Greater revenues and costs imply wider variations in profits, therefore increased risk, as the example below illustrates.

We consider four cases, listed below:

Case 1 - Small electricity distribution company, no FDPS: Rate base: Equity $=\$ 100$, Debt $=$ $\$ 300$.

Case 2 - Large electricity distribution company, no FDPS: Rate base: Equity $=\$ 200$, Debt $=$ $\$ 600$.

Case 3 - Large electricity distribution company, with FDPS: Rate Base: Equity $=\$ 100$, Debt $=\$ 300, \mathrm{FDP}=\$ 400$.

Case 4 - Large electricity distribution company, no FDPS, high leverage: Rate Base: Equity = $\$ 100$, Debt $=\$ 700$.

Companies 1 and 2 have the same capital structure (25\% equity and $75 \%$ debt) but different sizes (as measured by the value of their assets). Company 3 is of the same size as company 2, but half of its assets are in the form of FDPS. And company 4 has the same size as companies 2 and 3 but a different capital structure (12.5\% equity, $87.5 \%$ debt, no FDPS).

To keep things simple, we assume there is only revenue risk (that is, revenue changes with the state of the world, but cost doesn't) and consider three scenarios: Expected, when the company's revenue is the required revenue set by the regulator; Recession, when revenue is $5 \%$ lower than expected; and Boom, when revenue is $5 \%$ higher than expected.

In the calculations that follow, we use a 10\% interest rate and a $20 \%$ regulatory cost of capital. The first table presents a simplified income statement for company 1 under the three scenarios:

Table 1: Small company, no FDPS

\begin{tabular}{llll}
\hline Income Statement & Recession & Expected & Boom \\
\hline Revenue & 475 & 500 & 525 \\
Cost & 450 & 450 & 450 \\
Interest payments & 30 & 30 & 30 \\
Profit & -5 & 20 & 45 \\
Profit/Equity & $-5 \%$ & $20 \%$ & $45 \%$ \\
Standard Deviation & $20 \%$ & &
\end{tabular}

Notice that the investor earns a 20\% return in the expected scenario, as established by the regulator, and that she bears a risk, as measured by the standard deviation of the returns, of $20 \%$. 


\section{Asia Pacific Journal of Advanced Business and Social Studies \\ ISBN (eBook): 9780994365675 । ISSN : 2205-6033 \\ Year: 2017 , Volume: 3, Issue: 2}

The next table shows the outcomes for company 2 under the different scenarios:

Table 2: Large company, no FDPS

\begin{tabular}{llll}
\hline Income Statement & Recession & Expected & Boom \\
\hline Revenue & 950 & 1000 & 1050 \\
Cost & 900 & 900 & 900 \\
Interest payments & 60 & 60 & 60 \\
Profit & -10 & 40 & 90 \\
Profit/Equity & $-5 \%$ & $20 \%$ & $45 \%$ \\
Standard Deviation & $20 \%$ & & \\
\hline
\end{tabular}

Notice that the financial picture of company two is very similar to that of company 1. The investor earns the same returns and bears the same risk regardless of where he invests.

When the company is large and 50\% of its assets are FDPS (case 3), the picture changes, as shown in the table below. The risk borne by investors is almost twice what they bear when they invest in company 2.

Table 3: Large company, 50\% FDPS

\begin{tabular}{llll}
\hline Income Statement & Recession & Expected & Boom \\
\hline Revenue & 902.5 & 950 & 997.5 \\
Cost & 900 & 900 & 900 \\
Interest payments & 30 & 30 & 30 \\
Profit & -27.5 & 20 & 67.5 \\
Profit/Equity & $-28 \%$ & $20 \%$ & $68 \%$ \\
Standard Deviation & $39 \%$ & & \\
\hline
\end{tabular}

The last case, that of a large company with no FDPS but high leverage, is presented in the next table. 
Table 4: Large company, no FDPS, high leverage

\begin{tabular}{llll}
\hline Income Statement & Recession & Expected & Boom \\
\hline Revenue & 940.5 & 990 & 1039.5 \\
Cost & 900 & 900 & 900 \\
Interest payments & 70 & 70 & 70 \\
Profit & -29.5 & 20 & 69.5 \\
Profit/Equity & $-30 \%$ & $20 \%$ & $70 \%$ \\
Standard Deviation & $40 \%$ & & \\
\hline
\end{tabular}

What stands out immediately is how close case 4 resembles case 3 , as far as return on equity and risk for investors are concerned. That establishes a parallel between companies with significant FDPS and companies that make relatively more use of debt financing. We will elaborate on this idea later in the paper.

The conclusion of this analysis is that the presence of FDPS increases investor risk significantly, a risk for which he is not being compensated, since the regulatory return on capital is the same regardless of whether the company possesses FDPS or not. A likely consequence of this situation is that the distribution company may attempt to replace FDPS with new plant as soon as possible, which represents an unnecessary financial burden for consumers, who will have to pay a return of (depreciation) and on (cost of capital) the new investments. Society at large will also lose welfare, for assets that are still operational will be discarded and resources that could be employed in other economic activities will be used to acquire the new assets to replace them. ${ }^{1}$

\section{Calculating the rate of return on FDPS}

Having established that FDPS generates extra risk, we use two different approaches to address the issue. The economic approach argues that investors must earn at least the opportunity cost of their investments, which equals the remuneration they would obtain by investing in assets of similar risk. In a regulated industry such as electricity distribution, investors who are not able to earn at least their opportunity cost have an incentive to divert investments away. On the other

\footnotetext{
${ }^{1}$ One could ask whether investors are being compensated for the risk generated by the depreciated value of partially depreciated assets, which is not included in the rate base either. The answer is yes. However, regulators in developing countries typically use the international Capital Asset Pricing Model (CAPM) to determine the Weighted Average Cost of Capital (WACC) investors are entitled to. The international CAPM calculates the return investors require to purchase stock shares or bonds of electricity companies whose rate base has partially depreciated assets, and thus includes compensation for all the risks they bear, including those associated with the existence of those partially depreciated assets. What the international CAPM does not capture is the remuneration for the risk of holding FDPS.
} 
hand, investors should not be allowed to earn more than their opportunity cost, for that would likely lead to an ("unfair") financial burden on consumers.

The financial approach says that capital invested in different businesses with similar risks should earn the same return; otherwise, investors will migrate from lower return assets to higher return assets. The process only stops when returns (in equilibrium) are equalized.

It is patent that the two approaches lead to the conclusion that investors should earn a return on their investments equal to that of investments with similar risk. In what follows, we develop three models that allow us to actually calculate that rate of return.

\subsection{Financial model}

We first develop a model based on the financial approach and apply it to FDPS. As discussed earlier, regulators around the world calculate the rate of return per unit of capital invested as

$$
r_{p}=r_{f}+r_{p}^{r},
$$

where $r_{p}$ is the rate of return on equity (cost of equity), $r_{f}$ is the risk-free interest rate, and $r_{p}^{r}$ is the risk premium. The product of risk premium and investment equity is the remuneration investors receive for bearing the risk of investing in a regulated company.

Before we proceed, we need to discuss an important distinction between the risk generated by FDPS and that generated by assets in the rate base. Contrary to rate base assets, FDPS does not lead to an increase in required revenue on account of depreciation and return on capital. Therefore, these two types of asset generate different risks per unit of capital. One way around this problem is to find a unit of (rate base) capital that is equivalent to one unit of FDPS as far as the risk generated is concerned. We will call it the FDPS-equivalent capital.

The risk born by an investor who puts money into a regulated company is that associated with the variance of his income, which in turn comes from the variance of the company's revenues and costs. Without loss of generality, we consider a scenario where there is only revenue risk. ${ }^{2}$

A reasonable simplification is to assume that O\&M costs, depreciation and return on capital are all proportional to the value of assets in the rate base. In addition, it makes sense to assume that the impact on O\&M costs of an additional unit of capital is the same regardless of whether the asset is part of the rate base or not.

Now let $\lambda$ be the ratio between FDPS and all assets in service (AIS). The share of O\&M costs due to the presence of FDPS is $\lambda \times \mathrm{O} \& \mathrm{M}$. Let $M$ be the rate base capital that generates the same amount of risk as FDPS, and define $\theta$ as the ratio between $M$ and AIS. Under the proportionality assumption made earlier, the increase in required revenue driven by $M$ is $\theta\left(\mathrm{O} \& \mathrm{M}+D+A \times r_{p}\right)$. Since there is only revenue risk, we have:

\footnotetext{
${ }^{2} \mathrm{~A}$ full analysis where risk is measured as the standard deviation of returns and the FDPS-equivalent is obtained under different assumptions about the probability distributions of revenue and cost can be obtained from the authors upon request.
} 


$$
\begin{aligned}
& \lambda \times \mathrm{O} \& \mathrm{M}=\theta\left(\mathrm{O} \& \mathrm{M}+D+A \times r_{p}\right) \\
& \Rightarrow \frac{\mathrm{FDPS}}{\mathrm{AIS}} \times \mathrm{O} \& \mathrm{M}=\frac{M}{\mathrm{AIS}}\left(\mathrm{O} \& \mathrm{M}+D+A \times r_{p}\right) \\
& \Rightarrow M=\mathrm{FDPS} \times \frac{\mathrm{O} \& \mathrm{M}}{\mathrm{O} \& \mathrm{M}+D+A \times r_{p}} .
\end{aligned}
$$

A second adjustment needs to be made to the FDPS before we can calculate its rate of return. In a stationary state, on average half the value of the regulated company's assets have already been depreciated. This implies that only 50\% of the FDPS-equivalent needs to be remunerated. To better understand this, consider a company that purchases new plant to replace FDPSequivalent capital. Its rate base will grow by the full value of the new plant. For the first year after acquisition, the new plant will earn a return equal to the cost of capital times its full value. For the second year, it will earn a return on its non-depreciated value, and so on. Compare that to the remuneration a company would require to keep its FDPS-equivalent capital (instead of replacing it with new plant). If it receives that same remuneration every year, the depreciation of those assets is not factored in, and the company ends up being overcompensated. In order to account for the depreciation, we multiply the FDPS-equivalent capital by 50\%, which makes sense in a stationary state.

We are now ready to provide a formula for the return on FDPS:

$$
\text { Return on FDPS }=\left(r_{p}-r_{f}\right) \times 0.5 \times \gamma \times \frac{\mathrm{O} \& \mathrm{M}}{\mathrm{O} \& \mathrm{M}+D+A \times r_{p}} \times \mathrm{FDPS},
$$

where the factor 0.5 accounts for depreciation, $\mathrm{O} \& \mathrm{M} /\left(\mathrm{O} \& \mathrm{M}+D+A \times r_{p}\right)$ transforms FDPS into FDPS-equivalent, and $\gamma$ is equity's share of the company's FDPS-equivalent capital.

\subsection{Economic model 1}

We now make use of the economic approach, based on the idea of opportunity cost. The shareholders (investors) of a regulated company have two options. They can either keep the FDPS the company owns or replace it with new assets that will enter the rate base. Thus, the required revenue of the company should make shareholders indifferent between replacing and not replacing the company's FDPS. As explained earlier, the company should not earn a return on the full value of the FDPS, but only on half the value of its FDPS-equivalent capital, which from now on we will call net FDPS.

Let $A_{0}$ be the sum of the rate base with the net FDPS, and define $\alpha$ as the share of $A_{0}$ attributable to net FDPS. We calculate the company's required revenue in two cases: (i) Net FDPS is replaced with new assets; (ii) Net FDPS is not replaced.

In case (i), the rate base is equal to $A_{0}$. Suppose the company finances the acquisition of new assets through debt and equity in their regulatory proportions (i.e. the optimal capital structure defined by the regulator). Then its required revenue is equal to $R^{S}=C+r A_{0}+D^{S}$, where $r=\left[\gamma r_{P}+(1-\gamma) r_{B}\right] /(1-t)$ is the real cost of capital (rate of return) calculated by the WACC 
method, $t$ is the income tax rate, $B$ is the value of the company's debt, $P$ is equity, $\gamma=P /(P+B), r_{P}$ is the real cost of equity calculated by CAPM $3, r_{B}$ is the real cost of debt $4, C$ are operational and administrative costs, and $D^{S}$ is the depreciation of all assets, including old assets that have not been fully depreciated as well as new assets.

Notice that since $A_{0}=P+B$ we can write

$$
r A_{0}=\left[\frac{P}{P+B} r_{P}+\frac{B}{P+B} r_{B}\right]\left(\frac{P+B}{1-t}\right)=\frac{r_{P} P+r_{B} B}{1-t} .
$$

The required revenue then becomes

$$
R^{S}=C+\frac{r_{P} P+r_{B} B}{1-t}+D^{S}
$$

Consider now case (ii). The required revenue is given by

$$
R^{N S}=C+(1-\alpha)\left(\frac{r_{P} P+r_{B} B}{1-t}\right)+\alpha r_{1}(P+B)+D^{N S},
$$

where $D^{N S}$ is the depreciation of the assets that are not fully depreciated, that is, $(1-\alpha) A_{0}$. Notice that the operational and administrative costs do not change from case (i) to case (ii), and that the cost of capital now has two components. The first, $(1-\alpha)\left(\frac{r_{P} P+r_{B} B}{1-t}\right)$, is equal to the traditional return on capital, calculated as the WACC rate of return times the rate base. The second, $\alpha r_{1}(P+B)$, is an additional source of revenue equal to the product of the net FDPS, $\alpha(P+B)$, and a rate of return $r_{1}$. The rate of return $r_{1}$ is the unknown, i.e., the variable we want to solve for. In other words, we are expanding the rate base to include the net FDPS and calculating the return on this type of capital that makes shareholders indifferent between replacing and not replacing it.

What matters to shareholders is of course not the company's required revenue, but its net profit. In case (i), the net profit is given by

${ }^{3} r_{P}=\frac{1+r_{P}^{n}}{1+\pi^{U S}}-1$, where $r_{P}^{n}$ is the nominal cost of equity and $\pi^{U S}$ is the US inflation rate.

${ }^{4} r_{B}=\frac{1+r_{B}^{n}(1-t)}{1+\pi^{U S}}-1$, where $r_{B}^{n}$ is the nominal cost of debt, $t$ is the tax rate, and $\pi^{U S}$ is the US inflation rate. 


$$
\begin{aligned}
\pi^{S} & =R^{S}-C-D^{S}-\left(\frac{r_{B}}{1-t}\right) B-T^{S} \\
& =C+\frac{r_{P} P+r_{B} B}{1-t}+D^{S}-C-D^{S}-\left(\frac{r_{B}}{1-t}\right) B-T^{S} \\
& =\frac{r_{P} P+r_{B} B}{1-t}-\frac{r_{B} B}{1-t}-T^{S}=\frac{r_{P} P}{1-t}-T^{S},
\end{aligned}
$$

where $\left[r_{B} /(1-t)\right] B$ is interest paid and $T^{S}$ is taxes paid. Since taxes can be calculated as

$$
\begin{aligned}
T^{S} & =t\left[R^{S}-C-D^{S}-\left(\frac{r_{B}}{1-t}\right) B\right] \\
& =t\left[C+\frac{r_{P} P+r_{B} B}{1-t}+D^{S}-C-D^{S}-\left(\frac{r_{B}}{1-t}\right) B\right] \\
& =t\left[\frac{r_{P} P+r_{B} B}{1-t}-\frac{r_{B} B}{1-t}\right]=t\left(\frac{r_{P} P}{1-t}\right)
\end{aligned}
$$

we have

$$
\pi^{S}=\frac{r_{P} P}{1-t}-t\left(\frac{r_{P} P}{1-t}\right)=(1-t)\left(\frac{r_{P} P}{1-t}\right)=r_{P} P .
$$

In case (ii), net profit is given by

$$
\begin{aligned}
\pi^{N S}= & R^{N S}-C-D^{N S}-\left(\frac{r_{B}}{1-t}\right)(1-\alpha) B-T^{N S} \\
& =C+(1-\alpha)\left(\frac{r_{P} P+r_{B} B}{1-t}\right)+\alpha r_{1}(P+B)+D^{N S} \\
& -C-D^{N S}-\left(\frac{r_{B}}{1-t}\right)(1-\alpha) B-T^{N S} \\
& =(1-\alpha)\left(\frac{r_{P} P}{1-t}\right)+\alpha r_{1}(P+B)-t\left[(1-\alpha)\left(\frac{r_{P} P}{1-t}\right)+\alpha r_{1}(P+B)\right] \\
& =(1-\alpha)\left(\frac{r_{P} P}{1-t}\right)(1-t)+\alpha r_{1}(P+B)(1-t) \\
& =(1-\alpha) r_{P} P+\alpha r_{1}(P+B)(1-t)
\end{aligned}
$$

It is important to point out that, in case (ii), the net profit of the company is not all the income shareholders earn. Since they do not need to invest new capital into the company, they can use it to buy a riskless asset and earn $r_{f} \alpha P$, where $r_{f}$ é the risk free interest rate. 
Therefore, the rate of return $r_{1}$ is the solution to the equation below, which makes the income earned by shareholders in cases (i) and (ii) the same:

$$
\begin{aligned}
& \pi^{S}=\pi^{N S}+\alpha r_{f} P \\
& \Rightarrow r_{P} P=(1-\alpha) r_{P} P+\alpha r_{1}(P+B)(1-t)+\alpha r_{f} P \\
& \Rightarrow \alpha r_{1}(P+B)(1-t)=r_{P} P-(1-\alpha) r_{P} P-\alpha r_{f} P \\
& \Rightarrow \alpha r_{1}(P+B)(1-t)=\alpha r_{P} P-\alpha r_{f} P \\
& \Rightarrow r_{F D P S}^{1}=\left(\frac{r_{P}-r_{f}}{1-t}\right)\left(\frac{P}{P+B}\right)
\end{aligned}
$$

The conclusion is that the rate of return on net FDPS should be equal to the product of the difference between the cost of equity and the risk free interest rate, before taxes (i.e., divided by $(1-t))$, and the equity over total capital ratio.

\subsection{Economic model 2}

Our last model is similar to model 2. The difference is that, instead of expanding the rate base to accommodate the net FDPS, we adjust the rate of return to be applied to the rate base.

The required revenue and the net profit of the regulated company in case (i) are the same as those obtained in the previous section.

In case (ii), however, both required revenue and net profit are different than before, for the rate base no longer includes the net FDPS. The required revenue and net profit become

$$
R^{2}=C+(1-\alpha)\left[\frac{r_{2} P+r_{B} B}{1-t}\right]+D^{N S} \text {. }
$$

and

$$
\begin{aligned}
& \pi^{2}=R^{2}-C-D^{N S}-\left(\frac{r_{B}}{1-t}\right)(1-\alpha) B-T^{N S} \\
& =C+(1-\alpha)\left[\frac{r_{2} P+r_{B} B}{1-t}\right]+D^{N S} \\
& -C-D^{N S}-\left(\frac{r_{B}}{1-t}\right)(1-\alpha) B-t(1-\alpha)\left(\frac{r_{2} P}{1-t}\right) \\
& =(1-\alpha) r_{2} P,
\end{aligned}
$$

The rate of return $r_{2}$ that equates shareholders' earnings in the two cases is the solution to the following equation: 


$$
\begin{aligned}
& \pi^{S}=\pi^{2}+\alpha r_{f} P \Rightarrow r_{P} P=(1-\alpha) r_{2} P+\alpha r_{f} P \\
& \Rightarrow(1-\alpha) r_{2} P=\left(r_{P}-\alpha r_{f}\right) P \\
& \Rightarrow r_{F D P S}^{2}=\frac{r_{P}-\alpha r_{f}}{1-\alpha}=r_{f}+\frac{r_{P}-r_{f}}{1-\alpha}
\end{aligned}
$$

The interpretation is that the risk premium should be levered by $1 /(1-\alpha)$. Since the CAPM risk premium is given by $\beta\left(-_{-}\right)$, where $\bar{r}_{M}$ is the average return of the market portfolio, this implies that the beta must be levered by $\frac{1}{1-\alpha}$.

Finally, the return on equity will be equal to

$$
\frac{(1-\alpha) r_{F D P S}^{2} P}{(1-t)}=\left(\frac{1-\alpha}{1-t}\right)\left(\frac{r_{P}-\alpha r_{f}}{1-\alpha}\right) P=\left(\frac{r_{P}-\alpha r_{f}}{1-t}\right) P \text {. }
$$

\section{Conclusion}

In this paper, we investigated an issue that seems to have been neglected both in practice and in theory, namely the lack of compensation for the risk generated by regulatory assets that are still in service but are not included in the rate base. In other words, the rate of return investors are allowed to earn when they invest in regulated companies typically does not include a premium for that type of risk. This is an important topic because the absence of such a risk premium may lead shareholders to divest their assets in regulated industries and potential investors to favor other industries.

We focused on one particular type of risky asset that a utility company cannot include in its rate base: Fully depreciated assets still in service. We showed that they generate risk for shareholders because they affect the utility's revenues and costs, thus its profits. We then developed a methodology to determine how the rate of return should be changed to account for that extra risk. Our methodology is comprised of three different models, one based on financial principles and two based on the idea of opportunity costs from Economics. The three models generate the same return on capital for investors, but to develop them separately illuminates different aspects of the problem.

There is much to be done to further investigate this topic. We are currently working on an empirical methodology to calculate the rate of return that accommodates the presence of risky assets not in the rate base. We will then apply both our theoretical models and our empirical model to data from the Brazilian electricity sector and compare the results. We also plan to take a closer look at the Finance literature on cost of capital and capital structure to search for connections to our methodology. 


\section{Asia Pacific Journal of Advanced Business and Social Studies \\ ISBN (eBook): 9780994365675 | ISSN : 2205-6033 \\ Year: 2017 , Volume: 3, Issue: 2}

\section{References}

i. $\quad$ Crew, M. \& Kleindorfer, P., 1999. Stranded Assets in Network Industries in Transition. In: M. Crew, ed. Regulation under increasing competition,. New York: Springer.

ii. Hausman, J. \& Myers, S., 2002. Regulating the United States Railroads: The Effects of Sunk Costs and Assymetric Risk. Journal of Regulatory Economics, 22(3), pp. 287-310.

iii. Joskow, P., 1996. Does Stranded Cost Recovery Distort Competition?. The Electricity Journal, 9(3), pp. 31-45.

iv. Kahn, A., 1998. The Economics of regulation. Cambridge: The MIT Press.

v. Kolbe, A., Tye, W. \& Myers, S., 1993. Regulatory risk: Economic principles and applications to natural gas pipelines and other industries. Boston: Kluwer Academic Publishers.

vi. $\quad$ Lintner, J., 1965. The Valuation of Risk Assets and the Selection of Risky Investments in Stock Portfolios and Capital Budgets. Review of Economics and Statistics, 7(1), pp. 13-37.

vii. OFGEM, 2010. Handbook for implementing the RIIO model, London: Office of Gas and Electricity Markets.

viii. $\quad$ Sappington, D. \& Weisman, D., 2010. Price cap Regulation: What Have We Learned from 25 Years of Experience in the Telecommunications Industry?. Journal of Regulatory Economics, Volume 38, pp. 227-257.

ix. Sharpe, W., 1964. Capital Asset Prices: A Theory of Market Equilibrium under Conditions of Risk. Journal of Finance, 19(3), pp. 425-442. 